\title{
Quality of Early Childhood Care and Education in Jigjiga, Harar and Dire-Dawa Cities of Ethiopia
}

\author{
Beide Melaku* (PhD), Yigzaw Haile (PhD) \\ College of Education and Behavioral Study, Jigjiga University, Jigjiga, Ethiopia
}

*Corresponding Author: Beide Melaku, College of Education and Behavioral Study, Jigjiga University, Jigjiga, Ethiopia

\begin{abstract}
The study set out to assess the quality of Early Childhood Care and Education (ECCE) in DireDawa, Harar and Jigjiga cities of Ethiopia. The notion of quality in education can be explored with reference to conceptual frameworks that describe education. In this study, an Input-Process-Output framework was used to form the basis for defining the quality of ECCE. Employing a mixed method research design, 15 preschool centers (seven government-run and eight of them non-governmental) were selected for the study. Fifteen preschool teachers, six grade one homeroom teachers, and thirty children attending preschool were participants of the study. A semi-structured interview, an observation checklist, and a questionnaire were used to collect data. The result of the study indicated the presence of problems that were common across almost all of the preschool centers. The problems included inadequate indoor and outdoor play materials and playgrounds, lack of ECCE curriculum and syllabus, poor planning and management practices, large number of student per class, and shortage of trained teachers. None of the observed preschools were found to be friendly for children with disabilities. Five ECCE quality indicators were measured: Health, Nutrition, Personal care, and Routine, Protective Care and safety, Organization and Management, Children's Learning Opportunities, Assessment and reporting, and Managing Quality System. The composite mean value of these quality indicators indicated that the practice was intermediate. The lowest mean score was found in government pre-school centers. Moreover, significance difference was observed between government and non-government pre-school centers in their health, nutrition, personal care and routine practices at $t(6.0)=-$ 3.55, $P<0.05$, and organization and management practices $t(7.69)=-3.59, P<0.05$. Furthermore, the testament of grade one teachers indicated that those who had preschool experiences were better in cognition, language, and academic achievement than those who had not. On the basis of the findings, the study recommended the government to institute a quality control monitoring system and practice to improve quality of education at ECCE centers.
\end{abstract}

Keywords: Preschool; Quality Education; ECCE

\section{BACKGROUND OF THE STUDY}

Early childhood development is a platform for the later children development. Children's experience in early childhood education program has a strong impact on their later physical, social, emotional, moral and intellectual development (MoE, 2010). It is also expressed that children who receive good care and nurture during the early years of life are less likely to suffer illnesses, repeat grades, drop out of school, or require remedial services later in life (UNICEF, 2001). It is important to provide a language-rich environment for children that provide the basis for the child being able to read in the future.

In research, it was found that early childhood period is a time in which mental advances at a pace greater than any other stage in life. To ascertain this fact, research evidences on childhood development revealed that by the age of $2 \frac{1}{2}$ years, a child's brain has achieved $50 \%$ of its adult weight; and by the age of 5 , the brain has grown to $90 \%$ of its adult weight. The stage by its nature is encircled by different systems that have effects on children's development. In the systems, different agents interactively influence children's development. These are: family, teachers, principals, caregivers, culture, economic conditions of the country, political ideology and other parts of the ecology (Bruce \& Meggitt, 2006).

On the bases of these facts, countries have been giving emphasis to this area. This is even stipulated well in Education for All [EFA] (UNICEF, 2015) goals. Early childhood care and education is stated 
as the first goal from other goals. The goal tries to give attention to expansion and the way to improve early childhood care and education in different countries. The Sustainable Development Goal also provides much emphasis on the quality of early childhood care and education program (UN, 2016). Besides, it was expounded that investment in early childhood care and education results strong bodies, mind, optimal wiring and functioning of brain, encourage values of living together, beneficial effect on school preparedness and later learning (UNICEF, 2015).

Research further unlocked that the first six to seven years of age in the life cycle are ideal periods and most crucial to ground burly base to learn and develop fundamental skills and competencies, since a right start at early age is planting seeds for tomorrow's productivity (Tsegai, 2015). In addition, early years of age are stated as the most significant to the formation of intelligence, personality and social behavior of children (Sooter, 2013).

To ensure what has been stated in research findings, working hard to improve the quality of ECCE programs is necessary. This is because quality preschool learning environment shapes holistic development of children's skills over the preschool years (Anders et al., 2012).

In Ethiopia, like other countries, emphasis has been given to the ECCE area though it is a recent phenomenon. The ECCE program or sector was left to private and non-government organizations (Education International, 2010; Woodhead, 2009).However, from time to time, the awareness of the government to the role of early childhood care and education to children development was recognized. Realizing the benefits, the Ethiopian government developed a national ECCE policy, strategy and guideline, and run the program well (MoE, 2010). The way to access ECCE for urban and rural areas are properly stipulated in the national policy. In this framework, the domain and concentration areas of the policy are stated in the four pillars. These are: parental education, early stimulation and education, community-based kindergarten education and non-formal school readiness.

Similarly, to achieve the intention of the policy, the Ministry of Education has made pre-primary education a priority in its Education Sector Development Program [ESDP V] (MoE, 2016). The document includes strategic targets and objectives for pre-primary education over the five years 20162019/20. By the end of GTP I, preschool gross enrolment rate was 35\%. The government plans to expand the coverage to $80 \%$ in GTP II.

To make the program attain its objective, and in a way to ensure its quality, exploring the quality status of ECCE centres is important. This would put a foundation to develop intervention strategy for these areas.

\section{Statement of The Problem}

The aim of ECCE is to provide quality early childhood services for children four to six years. However, findings revealed many factors that affect quality preschool delivery. Most of the preschools are located in unsafe places or are not appropriate for preschool education because the facilities were not in line with the health and developmental needs of young children. Some centers lack potable water and could be environmentally inadequate due to lack of spaces for play and learning because most of them operate in buildings not originally constructed for that purpose. There is lack of children's books, toys and other relevant educational materials in some of these preschools (Tsegai, 2015).

Another study proved that lack of play materials, space for free movement, play based learning and indigenous materials are the characteristics of the government preschools (Yigzaw \& Abdirehman, 2017). Local materials, indoor and outdoor games are also observed as a serious problem in ECCE centers. These all do have a direct influence on the quality of ECCE program as well as hinder the pace of growth and development of the children in all domains. The ECCE input (indigenous child indoor and outdoor games, physical environment of ECCE, instructional materials, availability of child books, learning materials, teacher's training and the ECCE curriculum relevance and its relation with grade one), process (teaching methodology, assessment, involvement of parents) and output (contributions of ECCE such as achievement of children in grade one, and their readiness to school) have a direct impact on the quality of ECCE programs. These problems and other issues directly affect the gross enrolment rate of the country if the program does not keep its quality. Besides, it will be gloomy situation if the quality status is not studied. It will also affect the process to have consistent intervention in the program if the problem as whole is not investigated. There will not be also a 
platform to share good experience of different government and private ECCE schools if the status of the schools are not investigated as well as explored its quality. For the very vantage point expressed above, this research is planned to answer the following basic research questions and address the following objectives:

- What is the quality of preschool education in relation to ECCE inputs?

$>$ Examine educational qualification of preschool teachers.

$>$ Examine instructional provision and environmental set-up of the preschools

$>$ Explore the availability of ECCE related official documents.

- What is the quality of ECCE practices in relation to the process framework?

$>$ Examine health, nutrition and personal care routine in preschool centers.

$>$ Explore organization and management system of preschool centers.

$>$ Examine the teaching methodology the teachers apply in ECCE centers.

$>$ Explore assessment and evaluation systems of ECCE centers.

- What are the contributions of ECCE schools in relation to output issues?

$>$ Explore the benefit of ECCE program for the children's later learning and development.

\section{RESEARCH METHODOLOGY}

\subsection{Design}

The purpose of the study is to gain comprehensive insight about quality of Early Childhood Care and Education in Jigjiga, Harar, and Dire-Dawa cities of Ethiopia. Both qualitative and quantitative methods (mixed design) were used in the study. Mixed methods research is a research design in which the researchers collect, analyzes, and integrates both quantitative and qualitative data in a study.

\subsection{Participants}

For convenience of the researchers, Jigjiga, Dire-Dawa, and Harar cities were ideal sites for the research. Hence from the three sites, government owned, private investor owned, NGO owned and faith-based missions run pre-primary and primary schools were selected for inclusion in the study. Through maintaining proportionality, schools were selected through stratified and simple random sampling techniques from the three cities and sectors. As a result, seven government and eight nongovernment preschools (also known as O-classes) were selected for the study. Once schools were selected for inclusion in the study, 15 preschool (O-class) teachers, 6 grade-one teachers, and 30 preschool children participated in the study.

\subsection{Data Collection Instruments}

\subsubsection{Quantitative Tools}

In order to collect quantitative data, different types of instruments were used. Namely: Health, Nutrition, and Personal Care and Routine Scale (15 items), Protective Care and Safety Scale (11 items), Preschool Organization and Management Scale (39 items), Children Assessment and Outcome Measurement Scale (13 items), and Preschool Managing to Support Quality System Scale (13 items). Under it, there were 26-sub scales. All sub scales were assessed with responses ranging from 'Not Met', through 'Partially Met' to 'Fully Met'.

\subsubsection{Qualitative Tools}

In depth interviews were conducted with grade 1 and grade 2 homeroom-teachers and preschool teachers. There were 7 interview guide questions that focused on seven developmental domains. These were cognitive language, social, emotional, moral, fine motor and academic achievements. Based on these developmental domains, grade one teachers were requested to compare those children who had and had not preschool experiences. Moreover, six years old preschool students from government and non-government preschool centers were asked to perform different tasks in different academic areas i.e. letter naming, counting number (1-30), matching and identifying mathematical shapes, identifying math symbols, identifying position of objects (over \& under), color recognition 
(Red, yellow, green), comparison of size (big Vs small, tall Vs short, same Vs different), name and sequence of date, and tracing and coloring different mathematical pictures.

Moreover, 30 observation guide questions were used to assess the overall preschool classroom and compound. To assess outdoor environment, classroom space and buildings, and document related materials, 15, 9, and 6 observation guide questions were prepared respectively.

\subsection{Analysis of the Data}

After gathering the quantitative data, the next step was analysis of the data, which generally called for the use of frequency, percentage, mean, standard deviation and t-test. Analysis involves organizing, accounting for, and explaining the data; in short, making sense of the data in terms of the participants' definitions of the situation, noting patterns, themes, categories, and regularities (Cohen, Manion, \& Morrison, 2005). In addition, qualitative data were analyzed thematically based on the guideline proposed by Howitt and Cramer (2011).

\section{Results}

\subsection{Quality of ECCE Education along Input Aspects}

Table1 below shows the number of subjects taught in the preschool centers. While the majority (57\%) of government preschool centers taught five subjects, the remaining $(43 \%)$ taught four subjects. In the case of non-government preschool centers, $63 \%$ of them taught five subjects and the remaining $25 \%$ and $12 \%$ taught six and seven subjects respectively.

Table1. Number of Subjects Children Learn in ECCE Centers

\begin{tabular}{|l|c|c|c|c|c|c|c|c|}
\hline \multirow{3}{*}{ Centre Type } & \multicolumn{7}{c|}{ Number of Subjects } \\
\cline { 2 - 10 } & \multicolumn{2}{|c|}{ 4 Subject } & \multicolumn{2}{c|}{ 5 Subject } & \multicolumn{2}{c|}{ 6 Subject } & \multicolumn{2}{c|}{ 7 Subject } \\
\cline { 2 - 10 } & $\%$ & Freq. & $\%$ & Freq. & $\%$ & Freq. & $\%$ & Freq. \\
\hline Government & $43 \%$ & 3 & $57 \%$ & 4 & $0 \%$ & 0 & $0 \%$ & 0 \\
\hline Non-Government & $0 \%$ & 0 & $63 \%$ & 5 & $25 \%$ & 2 & $12 \%$ & 1 \\
\hline
\end{tabular}

Freq.: Frequency

Regarding number of students taught in a classroom it was found that in $71 \%$ of government preschool centers51-70 students were taught in a single classroom while the number of students per classroom reached as high as71-90 students per classroom in the remaining $29 \%$ of the government preschool centers. In contrast, $57 \%$ of non-government preschool centers taught 30-50 students per classroom while $37.5 \%$ of them taught51-70 students per classroom (See Table 2 below).

Table2. Number of students per classroom and center type

\begin{tabular}{|l|c|c|c|c|c|c|}
\hline \multirow{2}{*}{ Center Type } & \multicolumn{3}{c|}{ Number of Students } \\
\cline { 2 - 7 } & \multicolumn{2}{|c|}{$\mathbf{3 0 - 5 0}$} & \multicolumn{2}{c|}{$\mathbf{5 1 - 7 0}$} & \multicolumn{2}{c|}{$\mathbf{7 1 - 9 0}$} \\
\cline { 2 - 7 } & $\%$ & Freq. & \%req. & \% & Freq. \\
\hline Government & $0 \%$ & 1 & $71 \%$ & 5 & $29 \%$ & 2 \\
\hline Non-Government & $57 \%$ & 4 & $37.5 \%$ & 3 & $12.5 \%$ & 1 \\
\hline Freq.: Frequency & & & & & & \\
\hline
\end{tabular}

\subsection{Educational Background of Preschool Teachers}

Regarding the highest educational level attained by preschool teachers, Table 3 below show the majority $(88 \%)$ of preschool teachers attained Diploma level education whereas few of them $(12 \%)$ attained a Bachelor degree. Looking at preschool teachers' field of study, none were found to come from an ECCE background. However, half of the preschool teachers reported to have received some form of in-service training on ECCE. The other half however has not had the chance to receive ECCE training though.

Table3. Preschool Teachers' Education Status

\begin{tabular}{|c|c|c|c|c|c|c|c|c|c|c|c|}
\hline \multicolumn{4}{|c|}{ Education Status (Head Teachers) } & \multicolumn{4}{|c|}{ Teachers' Field of Specialization } & \multicolumn{4}{|c|}{ In-service ECCE Training } \\
\hline \multicolumn{2}{|c|}{ Diploma } & \multicolumn{2}{|c|}{ Degree } & \multicolumn{2}{|c|}{ ECCE } & \multicolumn{2}{|c|}{ Other } & \multicolumn{2}{|c|}{ Yes } & \multicolumn{2}{|c|}{ No } \\
\hline$\%$ & Freq. & $\%$ & Freq. & $\%$ & Freq. & $\%$ & Freq. & $\%$ & Freq. & $\%$ & Freq. \\
\hline $88 \%$ & 13 & $12 \%$ & 2 & $0 \%$ & 0 & $100 \%$ & 15 & $53 \%$ & 8 & $47 \%$ & 7 \\
\hline
\end{tabular}




\subsection{Indoor Environment of the Preschool Centers}

In this research, ECCE guides, documents, classroom space and building out of classroom compound or preschool compound, teacher's qualification in protective care and safety were measured through an observation guide, a questionnaire and an interview. The result obtained from the observation guide revealed that the majority (87\%) preschools classrooms had adequate lighting and were well ventilated with enough windows to allow a good flow of air. Chairs and desks were also age appropriate in $80 \%$ preschool centers.(see Table 4).In contrast, more than half (53\%) of preschool centers did not have adequate classroom space for free movement of children. This was due to the large number of students taught per classroom.

Table4. Results from an Indoor Observation of the ECCE Centers

\begin{tabular}{|c|c|c|c|c|}
\hline \multirow{2}{*}{$\begin{array}{c}\text { Space, building } \\
\text { (size, ventilation, light) }\end{array}$} & \multicolumn{2}{|c|}{ Yes } & \multicolumn{2}{|c|}{ No } \\
\hline & $\%$ & Freq. & $\%$ & Freq. \\
\hline Provision of adequate light and ventilation in the rooms & $87 \%$ & 13 & $13 \%$ & 2 \\
\hline Adequate classroom space for free movement of children & $47 \%$ & 7 & $53 \%$ & 8 \\
\hline Comfortable chairs and desks to use & $80 \%$ & 12 & $30 \%$ & 3 \\
\hline Keep the class clean & $100 \%$ & 15 & $0 \%$ & 0 \\
\hline Adequate space to place children's learning materials & $67 \%$ & 10 & $33 \%$ & 5 \\
\hline Adequate space for teachers to put their materials & $73 \%$ & 11 & $27 \%$ & 4 \\
\hline Teachers have their own office & $27 \%$ & 4 & $73 \%$ & 11 \\
\hline Schools located in a place away from the sources of excessive noise & $73 \%$ & 11 & $27 \%$ & 4 \\
\hline The seating arrangement of students allows free movement & $60 \%$ & 9 & $40 \%$ & 6 \\
\hline
\end{tabular}

As indicated in Table 4, Sixty seven percent of preschool centers had adequate space to put children's learning materials. While $73 \%$ of teachers from the observed schools had space to put their materials, the rest $27 \%$ of preschools center teachers did not have their own separate or staff office. In relation to locations of preschool centers, $27 \%$ of preschools were found to be located in areas with excessive noise. The majority $73 \%$ of preschools were however located away from noise. The seating arrangement of students allows free movement in $60 \%$ of the observed schools while the rest $40 \%$ were found to be less comfortable for free movement. In some observed schools, children's seating arrangement was in one-to-five arrangements that help facilitate discussion and interaction among the children.

\subsection{Outdoor Environment of the Preschool Centers}

Regarding availability of an out of classroom compound, the majority (80\%) of the preschool centers were found to lack out of classroom compound sand outdoor playing materials. This was more characteristic of the government preschool centers observed in the study. Moreover, almost all of the observed preschool centers were not friendly for children with disabilities. In contrast, the majority $(60 \%)$ of the centers had adequate space for outdoor play and activities. Nonetheless, the remaining $40 \%$ preschools lack enough playgrounds. All preschool centers had clean surrounding in and around school and all of them had designated areas for garbage disposal.

Table5. Results from an Outdoor Observation of ECCE Centers

\begin{tabular}{|l|r|r|r|r|}
\hline \multicolumn{1}{|c|}{ Out of Classroom Observation } & \multicolumn{2}{|c|}{ Yes } & \multicolumn{2}{|c|}{ No } \\
\cline { 2 - 4 } & \multicolumn{1}{|c|}{$\%$} & Freq. & \multicolumn{1}{|c|}{$\%$} & Freq. \\
\hline Availability of equipment for outdoor play/ activities for all children & $20 \%$ & 3 & $80 \%$ & 12 \\
\hline $\begin{array}{l}\text { ECCE center is disabled- friendly and allows easy access for children } \\
\text { with special needs }\end{array}$ & $0 \%$ & 0 & $100 \%$ & 15 \\
\hline Adequate space available for outdoor play and activities. & & & \\
\hline Clean surroundings in and around center & $60 \%$ & 9 & $40 \%$ & 6 \\
\hline Designated area for garbage disposal, dustbins, brooms etc. & $0 \%$ & 15 & $0 \%$ & 0 \\
\hline No hazards, such as uncovered drains/ wells, around the ECCE center. & $100 \%$ & 15 & 0 & 0 \\
\hline ECCE Centre is located in a safe place. & $73 \%$ & 11 & $27 \%$ & 4 \\
\hline Safety level of building is adequately maintained. & $60 \%$ & 9 & $40 \%$ & 6 \\
\hline ECCE center building is maintained in a good condition. & $20 \%$ & 3 & $80 \%$ & 12 \\
\hline There is clean water source in the school compound & $87 \%$ & 13 & $13 \%$ & 2 \\
\hline The water source is cleanly handled & $60 \%$ & 9 & $40 \%$ & 6 \\
\hline The school has latrine service for children & $60 \%$ & 9 & $40 \%$ & 6 \\
\hline The latrine is safe and age appropriate to all children & $100 \%$ & 15 & $0 \%$ & 0 \\
\hline There is clean water which students can use after latrine & $87 \%$ & 13 & $13 \%$ & 2 \\
\hline Fence and entrance with door & $60 \%$ & 9 & $40 \%$ & 6 \\
\hline
\end{tabular}


Regarding the location of the preschool centers, $60 \%$ of the schools were located in safe areas while the reaming $40 \%$ were located in less safe and noisy areas. From a safety point of view, $80 \%$ of classroom buildings in the schools have not been adequately maintained.

Clean water was available in $60 \%$ of the observed preschool centers, and it was handled cleanly. Likewise, all preschools had latrine service for children. However, 13\% of the latrines were age inappropriate and $40 \%$ lacked access to clean water for hand washing after use of the latrines. Although separate fences and gates are necessary for preschool centers, $47 \%$ of the observed preschool centers lacked fences and separate gates.

\subsection{Availability of Preschool Related Official Documents}

Regarding the availability of ECCE curriculum documents at preschool centers, only $27 \%$ of the observed preschool centers had an ECCE Syllabus while the majority (73\%) operated without an ECCE syllabus. Those schools that had the preschool curriculum document (syllabus) were located in Dire Dawa city administration. This was due to the City Administration Education Bureau's efforts in translating the national preschool curriculum into Oromifa and Somali language and distributing copies to preschools in the city.

In relation with children's education data, $87 \%$ of preschool centers have recorded document to follow up children's' progress. Nevertheless, in 53\% of preschools, children's learning activities were not documented well. Likewise, parent- teacher communication books in $67 \%$ of observed ECCE centers do not have documented entries on information exchange between parents and teachers. Observation of preschool teachers' lesson plans also indicated that $80 \%$ of lesson plans were not up to the standard and holistic. The majority of the lesson plans emphasized on cognitive and psychomotor domains of learning outcomes.

Table6. Availability of ECCE Related Official Documents

\begin{tabular}{|c|c|c|c|c|}
\hline \multirow[b]{2}{*}{ Document observation } & \multicolumn{2}{|c|}{ Yes } & \multicolumn{2}{|c|}{ No } \\
\hline & $\%$ & Freq. & $\%$ & Freq. \\
\hline Has the Ecce curriculum at hand & $27 \%$ & 4 & $73 \%$ & 11 \\
\hline Has the syllabus at hand and use it & $27 \%$ & 4 & $73 \%$ & 11 \\
\hline Has recorded document to follow up child progress & $87 \%$ & 13 & $13 \%$ & 2 \\
\hline Has documented commentaries where parents \& facilitator exchanged & $33 \%$ & 5 & $67 \%$ & 10 \\
\hline Well documented children's learning activities & $47 \%$ & 7 & $53 \%$ & 8 \\
\hline $\begin{array}{l}\text { Lesson plan address cognitive, affective and psychomotor } \\
\text { development of children. }\end{array}$ & $20 \%$ & 3 & $80 \%$ & 12 \\
\hline
\end{tabular}

\subsection{Quality of ECCE Education along Process Aspects}

\subsubsection{Protective Care and Safety Practice in Preschools}

Protective care and safety was measured along areas of adult supervision, socio-emotional protection and physical safety through a three-point scale questionnaire where 1 indicated 'not met', 2 indicated 'partially met', and 3 indicated 'fully met' protective care and safety. Mean value for adult supervision was found to be 2.00 in government and 2.62 in Non-government preschool centers. The mean reports of socio-emotional protection was found to be 2.35 in government and 2.50 in nongovernment preschool centers.

Table7. Respondents' Mean Score on Protective Care and Safety

\begin{tabular}{|l|l|r|r|r|r|}
\hline \multirow{2}{*}{ NO } & \multirow{2}{*}{ Sub Domains } & \multicolumn{4}{|c|}{ Preschool Centre Type } \\
\cline { 3 - 6 } & & \multicolumn{2}{c|}{ Government } & \multicolumn{2}{c|}{ Non-Government } \\
\cline { 3 - 6 } & & Mean & \multicolumn{1}{c|}{ SD } & \multicolumn{1}{c|}{ Mean } & SD \\
\hline 1 & Adult supervision & 2.00 & .33 & 2.62 & .51 \\
\hline 2 & Socio-emotional protection & 2.35 & .60 & 2.50 & .53 \\
\hline 3 & Physical safety & 2.26 & .60 & 2.67 & .57 \\
\hline \multicolumn{2}{|c|}{ Average } & 2.20 & .54 & 2.59 & .54 \\
\hline \multicolumn{2}{|c|}{ Cumulative } & \multicolumn{5}{|c|}{ Mean= 2.39} & SD=.54 \\
\hline
\end{tabular}

SD: Standard Deviation

Similarly, the mean value of physical safety was 2.26 for government and 2.67 for non-government ECCE centers. Average mean score for government and non-government preschool centers compares 
at 2.20 and 2.59 respectively. In all sub domains, the mean score of government preschool centers was not higher than mean scores for non-government preschool centers. The t-score value, $t(4.3)=-4.76$, $\mathrm{P}<0.01$, showed the existence of a significant difference between government and non-government preschool centers in their protective and safety practices.

\subsubsection{Health, Nutrition, Personal Care and Routine}

The quality of health, nutrition, personal care and routine aspects of ECCEs was measured through a questionnaire. As can be seen from Table 8 below, in a four subscale, the composite mean score of the domain was 2.13 indicating that the practice was met partially. When we compare the practice of government and non-government preschool centers, it was found 1.65 and 2.61 respectively, and relatively the highest mean score was found from non-government preschool centers. In all sub domains, the mean response found from government preschool centers was low and below the composite means score. (Health 1.75, Nutrition 1.19, Hygiene 2.04 and Habit formation 1.83). The highest mean repose of the practice of the two sub domains (Hygiene 2.84, and Habit formation 2.94) were found from non-government preschool centers.

Table8. Respondents' Mean Response on Health, Nutrition, Personal Care \& Routine Domain

\begin{tabular}{|c|c|c|c|c|c|}
\hline \multirow{3}{*}{ NO } & \multirow{3}{*}{ Sub Domains } & \multicolumn{4}{|c|}{ Preschool Centre Type } \\
\hline & & \multicolumn{2}{|c|}{ Government } & \multicolumn{2}{|c|}{ Non-Government } \\
\hline & & Mean & SD & Mean & SD \\
\hline 1 & Health & 1.75 & .31 & 2.13 & .23 \\
\hline 2 & Nutrition & 1.19 & .90 & 2.55 & .35 \\
\hline 3 & Hygiene & 2.04 & .71 & 2.84 & .35 \\
\hline 4 & Habit Formation & 1.83 & 1.37 & 2.94 & .07 \\
\hline \multicolumn{2}{|c|}{ Average } & 1.65 & .82 & 2.61 & .25 \\
\hline \multicolumn{2}{|c|}{ Cumulative } & Mean $=2.13$ & $\mathrm{SD}=0.66$ & & \\
\hline
\end{tabular}

SD: Standard Deviation

The T-score result depicted that there was a significant difference between government and nongovernment preschool centers in their health, nutrition, personal care and routine practices at $\mathrm{t}(6.0)=-$ $3.55, \mathrm{P}<0.05$.

\subsubsection{Organization and Management Practice}

Regarding organization and management domain, Table 9 below show that cumulative mean value of the domain was 2.23 . The average mean value of government owned preschool centers mean $=2.01$ ) was lower than non-government preschool centers (mean= 2.45). Moreover, in their organization and management practices, significant differences were observed between government and nongovernment preschool centers at $\mathrm{t}(7.69)=-3.59, \mathrm{P}<0.05$.

Table9. Respondents' Mean Response on Organization and Management Domain

\begin{tabular}{|c|c|c|c|c|c|}
\hline \multirow{3}{*}{ NO } & \multirow{3}{*}{ Sub Domains } & \multicolumn{4}{|c|}{ Preschool Centre Type } \\
\hline & & \multicolumn{2}{|c|}{ Government } & \multicolumn{2}{|c|}{ Non-Government } \\
\hline & & Mean & SD & Mean & SD \\
\hline 1 & Program philosophy & 2.05 & 0.43 & 2.21 & 0.48 \\
\hline 2 & Documentation and safety & 2.09 & 0.42 & 2.33 & 0.65 \\
\hline 3 & Program planning & 2.30 & 0.75 & 2.53 & 0.59 \\
\hline 4 & Parent involvement & 1.84 & 0.48 & 2.63 & 0.50 \\
\hline 5 & Staffing & 1.77 & 0.40 & 2.54 & 0.45 \\
\hline \multicolumn{2}{|c|}{ Average } & 2.01 & 0.49 & 2.45 & 0.53 \\
\hline \multicolumn{2}{|c|}{ Cumulative } & & & Mean $=2.23$ & $\mathrm{SD}=0.51$ \\
\hline
\end{tabular}

SD: Standard Deviation

In this domain, the lowest mean value was found for parental involvement (Mean $=1.86)$ and staffing $($ mean $=1.77)$ in government preschool centers. The result revealed that parents and teachers communication about ECCE was loose, and needs of preschool teachers were not met. In the remaining sub scales of this domain, namely, program philosophy $($ mean $=2.06)$, documentation and safety $($ mean $=2.09)$, and program planning $($ mean $=2.30)$, the mean value of government owned preschool centers was neither lower nor higher than government preschool centers. 


\subsubsection{Assessment and Reporting Practices}

Table10. Respondents' Mean Score on Assessment and Reporting Domain

\begin{tabular}{|c|c|c|c|c|c|}
\hline \multirow{3}{*}{ NO } & \multirow{3}{*}{ Sub Domains } & \multicolumn{4}{|c|}{ Preschool Centre Type } \\
\hline & & \multicolumn{2}{|c|}{ Government } & \multicolumn{2}{|c|}{ Non-Government } \\
\hline & & Mean & SD & Mean & SD \\
\hline 1 & Assessment method and reporting & 1.81 & 0.38 & 2.06 & 0.41 \\
\hline 2 & Staff assessment & 1.49 & 0.42 & 1.84 & 0.38 \\
\hline \multicolumn{2}{|c|}{ Average } & 1.65 & 0.4 & 1.96 & 0.39 \\
\hline \multicolumn{2}{|c|}{ Cumulative } & \multicolumn{4}{|c|}{ Mean $=1.81$} \\
\hline
\end{tabular}

SD: Standard Deviation

Table 10 above indicates preschool teachers' mean response on reporting and measurement of ECCE programs. The mean value of assessment methods and reporting practice of government owned preschool centers was 1.81 which mean assessment and reporting practice was partially met or less. In both government and non-government preschool centers, it was found that staff arrangement and development practice mean value was low. This mean that the practice of staff evaluation and appraisal was not met partially. In their assessment and reporting practices there was no significant difference between government and non-government preschool centers at $\mathrm{t}(1.77)=-1.55 \mathrm{P}<0.05)$.

\subsubsection{Managing to Support Quality System}

The last quality process indicator domain was managing to support quality system. As can be seen from Table 11 below, the cumulative mean value of managing quality system was 1.64 . The lowest mean scores were found in teachers' education and opportunity for capacity building and monitoring and support supervision. The result of this domain show that the practice of CPD for preschool teachers was rarely conducted and monitoring was also done rarely. Moreover, the T-score value, $t$ $(1.00)=-.50, \mathrm{P}<0.05$, depicted that there was no significant difference between government and nongovernment preschool centers in their practices of management to support quality system.

Table11. Respondents' Men Score on Managing to Support Quality System Domain

\begin{tabular}{|c|c|c|c|c|c|}
\hline \multirow{3}{*}{ No } & \multirow{3}{*}{ Sub Domains } & \multicolumn{4}{|c|}{ Preschool Centre Type } \\
\hline & & \multicolumn{2}{|c|}{ Government } & \multicolumn{2}{|c|}{ Non-Government } \\
\hline & & Mean & SD & Mean & SD \\
\hline 1 & Teacher education and opportunity for capacity building & 1.76 & 0.40 & 1.68 & 0.35 \\
\hline 2 & Monitoring and supportive supervision & 1.44 & 0.24 & 1.68 & 0.54 \\
\hline \multicolumn{2}{|c|}{ Average } & 1.6 & 0.32 & 1.68 & 0.44 \\
\hline \multicolumn{2}{|c|}{ Cumulative } & \multicolumn{4}{|c|}{ Mean $=1.64 \quad \mathrm{SD}=0.38$} \\
\hline
\end{tabular}

SD: Standard Deviation

\subsection{Quality of ECCE Education along Output Aspects}

\subsubsection{Contributions of Preschool Education}

The output aspects of preschool education were measured through interviews conducted with grade one teachers. Teachers were asked to compare children with and without preprimary education experience in terms of their academic achievement and their cognitive, socio-emotional, language, and moral development. Almost all interviewees agreed that "Children who had no pre-primary education experience need more academic support than children who had experience."

With regard to their moral and socio-emotional development, all interviewees replied that those children who had preschool experience were in a better position in their moral and socio-emotional development than those children who had no preschool experience. About their moral development, interviewee two, with eight years of experience in preschool education, said that:

"When we compare those children who had preschool experience with those who did not, they are better in respecting classroom rules and regulations and know what is right and wrong in the classroom."

Regarding the importance of preschool education for children's socio-emotional development, interviewee four testified as follows: 
"Preprimary education creates the opportunity for children to know each other better and freely interact with each other. but those children without preschool experience face problems in social interaction. Through time when they become familiar with other children, they become friendly with other children."

The outcome of preschool education was also measured through comparing the cognitive development of children going to government and non-government preschools, and who had one year of preschool experience. Cognitive development was measured through letting children identify letters and numbers, match and identify different mathematical shapes (triangle, circle, and rectangle) and symbols, identify positions of objects and colors (red, yellow, and green), compare size (big Vs small, tall Vs short, same Vs different), and identify names and sequence of dates. As can be seen from Table 12 below, those children who had one year of preschool experience in non-government centers were better in their cognitive development than those in government preschool centers.

Table12. Preschool learning outcomes in government and non-government preschool centers

\begin{tabular}{|c|c|c|c|c|c|}
\hline \multirow[b]{2}{*}{ Learning Outcomes } & \multirow[b]{2}{*}{ Centre Type } & \multicolumn{2}{|c|}{ Yes } & \multicolumn{2}{|c|}{ No } \\
\hline & & Freq. & $\%$ & Freq. & $\%$ \\
\hline \multirow[t]{2}{*}{ Letter naming } & Government & 9 & $60 \%$ & 6 & $40 \%$ \\
\hline & Non-Government & 15 & $100 \%$ & & \\
\hline \multirow{2}{*}{$\begin{array}{l}\text { Counting number } \\
(1-30)\end{array}$} & Government & 8 & $53 \%$ & 7 & $47 \%$ \\
\hline & Non-Government & 13 & $87 \%$ & 2 & $13 \%$ \\
\hline \multirow{2}{*}{$\begin{array}{l}\text { Matching shapes } \\
\text { (Triangle, circle, rectangle) }\end{array}$} & Government & 14 & $93 \%$ & 1 & $7 \%$ \\
\hline & Non-Government & 15 & $100 \%$ & & \\
\hline \multirow{2}{*}{$\begin{array}{l}\text { Identifying Shapes } \\
\text { (Rectangle and Circle) }\end{array}$} & Government & 10 & $67 \%$ & 5 & $33 \%$ \\
\hline & Non-Government & 14 & $93 \%$ & 1 & $7 \%$ \\
\hline \multirow{2}{*}{$\begin{array}{l}\text { Identifying math symbols } \\
(+\&-)\end{array}$} & Government & 13 & $87 \%$ & 2 & $13 \%$ \\
\hline & Non-Government & 15 & $100 \%$ & & \\
\hline \multirow{2}{*}{$\begin{array}{l}\text { Identifying position of objects } \\
\text { (over \& under) }\end{array}$} & Government & 9 & $60 \%$ & 6 & $40 \%$ \\
\hline & Non-Government & 13 & $87 \%$ & 2 & $13 \%$ \\
\hline \multirow{2}{*}{$\begin{array}{l}\text { Color recognition } \\
\text { (Red, yellow, green) }\end{array}$} & Government & 12 & $80 \%$ & 3 & $20 \%$ \\
\hline & Non-Government & 15 & $100 \%$ & & \\
\hline \multirow{2}{*}{$\begin{array}{l}\text { Comparison of size } \\
\text { (big Vs small, tall Vs short, same Vs different) }\end{array}$} & Government & 8 & $53 \%$ & 7 & $47 \%$ \\
\hline & Non-Government & 14 & $93 \%$ & 1 & $7 \%$ \\
\hline \multirow[t]{2}{*}{ Name $\&$ sequence of date } & Government & 11 & $73 \%$ & 4 & $27 \%$ \\
\hline & Non-Government & 15 & $100 \%$ & & \\
\hline
\end{tabular}

In the study, the contributions of preschool education for pre-writing skill development and coloring were also measured through comparing those children who had no preschool experience with those who had one year of preschool experience. The findings revealed that almost all children who had one year of preschool experience were better in coloring shapes and tracing vertical, horizontal, and across than children who had no preschool experience (See the Picture below).

\section{Pre writing and coloring skill}
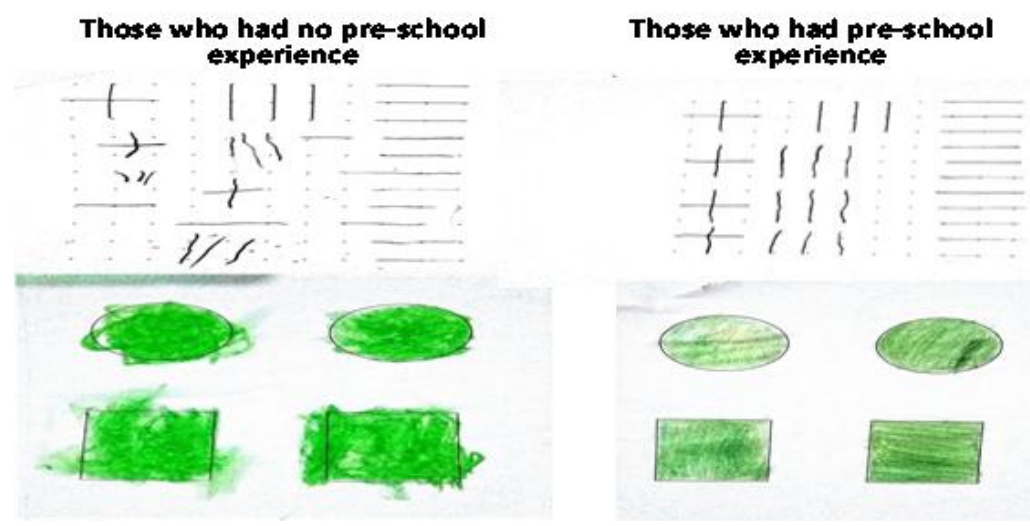


\section{CONCLUSiOnS}

Based on the above findings, the researchers conclude that:

- Compared with government run preschool centers, non-government preschool centers teach more subjects to children.

- Class size is larger at government preschools compared with non-government ones. Irrespective, class size do not meet MoE's standard for preschool education.

- In the majority of the preschool centers, teachers did not have the required qualifications to teach at preschools. Moreover, none of the teachers were trained in early childhood education.

- Concerning the indoor environment of preschools, most preschool centers lack adequate classroom space for free movement of children. This is even worse as preschools have large class sizes. Moreover, the majority of preschool centers do not have staff offices, places where staff can put their materials while in the classroom.

- Concerning the outdoor environment of preschools, the majority of the preschool centers fall short of materials for children. Severity of this shortage is observed more at government preschools. Moreover, the majority of the centers were not friendly for children with disability. Although all preschool centers had latrines, some were not age appropriate and others lacked clean water for hand washing after use.

- Regarding ECCE related official documents, the majority of preschool centers had no ECCE syllabus to refer to.

- In the majority of preschool centers, teachers lesson plans were not holistic and only focused on the cognitive and psychomotor aspects of development.

- Adult supervision was relatively better in non-government preschool centers compared with government preschools. That is, children in non-government preschool centers were supervised well than those at government preschool centers. Similarly, socio-emotional protection and physical safety of children was better in non-government preschools than those at government preschool centers. Non-government preschool teachers (care givers) were more sensitive to the children's needs and were able to provide emotional support to children better than teachers at government preschool centers.

- Concerning health, nutrition, personal care and routine, current preschool practice is below national standards set for ECCE. Nonetheless, non-government preschool centers were in a better position in adapting the physical environment to accommodate children's needs, cleaning latrines and maintaining the hygiene of classrooms, and discussing with parents to promote children's hygienic habit.

- Organization and management practices in preschool centers were not up to the standards in both government and non-government preschool centers. However, the non-government preschool centers were relatively better in their program philosophy, documentation, program planning, staffing and parental involvement. Regarding assessment and reporting, the practice was poor in both government and non-government preschool centers.

- Regarding management practice at preschools to support quality systems, teachers' professional development, capacity building at all levels, and career path for staff, the majority of preschool centers did not have well developed management practices.

- The findings of the study also indicate that children who had preschool experience were better in their cognitive skills (like counting and identifying numbers, matching shapes, identifying math symbols, color recognition, naming and sequencing of date).

- In many aspects of quality indicators, non-government preschool centers were in a better status than government ones.

\section{RECOMMENDATIONS}

In light of the results of the study, the research recommends important actions for Regional Education Bureaus (REBs). A major recommendation is for REBs to allocate adequate budget to preschool centers providing the resource needed to operate as per ECCE standards. REBs should also translate, adapt and distribute the national ECCE curriculum for all preschool centers and follow up with the 
implementations of ECCE policy, strategy, and syllabus on a regular basis. Facilities in the schools should be regularly monitored and inspected by Education Bureau ECCE supervisors. In order to alleviate the problem of qualified teachers in the area, universities and teacher training colleges should train ECCE professionals. Moreover, teachers at preschools need to receive regular in-service trainings on ECCE. All preschool centers need to be inclusive. Particularly, preschool education should also be designed to make the centers disability friendly and allow easy access for children with special needs. Moreover, parents and the community should be given opportunities to participate in preschool programs. Finally, the MOE, REBs and stakeholders should develop quality control guidelines and packages for preschool education, and regularly follow up with implementation.

\section{REFERENCES}

[1] Anders, et al. (2012). Home and preschool learning environments and their Relations to the development of early numeracy skills. Early Childhood Research Quarterly 27, 231-244

[2] Bruce, T., \& Meggitt, C. (2007). Child Care and Education. London: Hodder Headline Group.

[3] Cohen, L., Manion, L., and Morrison, K. (2005). Research Methods in Education (5 ${ }^{\text {th }}$ ). New York, Taylor \& Francis e-Library.

[4] Education International (2010). Early Childhood Education: A Global Scenario, A report on a study conducted by the Education International ECE Task Force Education International.

[5] Howitt, D. \& Cramer, D. (2011). Introduction to Research Methods in Psychology (3 $\left.{ }^{\mathrm{rd}}\right)$. England, Pearson Education Ltd.

[6] MoE(2010). Education Sector Development Program IV (ESDP IV; 2010/2011 - 2014/2015). Program Action Plan, Addis Ababa.

[7] MoE (2010).Strategic operational plan for early childhood care and education (ECCE) in Ethiopia, Addis Ababa, Ethiopia.

[8] MOE (2010). National Policy Frame-work for Early Childhood care and Education in Ethiopia. Addis Ababa, Ethiopia.

[9] MoE. (2015). Education Sector Development Program V (ESDP V) 2015/16 - 2019/20, Program Action Plan. Federal Ministry of Education. Addis Ababa

[10] Soote, T. (2013). Early childhood education in nigeria: issues and problems. Journal of Educational and Social Research Vol 3, No 5

[11] Tsegai Mulugeta(2015). Early child care and education attainment in Ethiopia: Current status and challenges. African Educational Research Journal, Vol. 3(2), pp. 136-142.

[12] UN (2016). The Sustainable Development Goals Report. New York

[13] UNESCO (2015). The State of Education For All 2000-2015: Achievements and challenges. (2 ${ }^{\text {nd }}$ Edd.) United Nations Educational, Scientific and Cultural Organization.

[14] UNICEF (2001). The state of the world's children. New York, USA

[15] Yigzaw Haile, \& Abdirahman Mohammed. (2017). Practices and challenges of public and private preschools of Jigjiga City Administration. International Journal of Research - Granthaalayah, 5(12), 1732 .

Citation: Beide Melaku, Yigzaw Haile. "Quality of Early Childhood Care and Education in Jigjiga, Harar and Dire-Dawa Cities of Ethiopia" International Journal of Humanities Social Sciences and Education (IJHSSE), vol 6, no. 2, 2019, pp. 11-21. doi: http://dx.doi.org/10.204 31/2349-0381.0602002.

Copyright: (C) 2019 Authors. This is an open-access article distributed under the terms of the Creative Commons Attribution License, which permits unrestricted use, distribution, and reproduction in any medium, provided the original author and source are credited. 